\title{
Social parasitism: the keys to the kingdom
}

\author{
M. Breed ${ }^{1}$
}

Published online: 7 January 2016

(C) International Union for the Study of Social Insects (IUSSI) 2016

How a species comes to exploit another species' social advantages for survival is a rich and highly textured area of inquiry. Perhaps the most well known example of socially parasitic species are the slave-making ants, which steal the brood of other ant species and effectively make them 'slaves' working for the benefit of the slave-makers. Other types of social parasites exist only as queens, which live within the colony of a host species. How one species evolves to take advantage of another's social system is an intriguing evolutionary question.

Intense discussion has focused on two very different models for how social parasites evolved. The first model proposes that social parasites evolve as sister species to their host. The social parasite is then initially similar to its host in communication and life history traits. This model is called Emery's rule; the main difficulty with this route to social parasitism is that when it is strictly applied speciation occurs within a population, without geographic isolation.

It is easier to accept a relaxed interpretation of Emery's rule, in which host and parasite are on the same very limited branch of a cladogram (evolutionary tree), but not necessarily sister species. Most supporting cases for Emery's rule involve the relaxed interpretation, as it may not require speciation originating in the same geographical area. Genetic and morphological studies suggest that at least the relaxed version of Emery's rule applies to many species of socially parasitic ants.

The second model invokes a common evolutionary ancestry, or clade that evolves with characteristics typical of

\footnotetext{
M. Breed

michael.breed@colorado.edu

1 Boulder, USA
}

certain kinds of social parasites, such as large size, a lack of foraging structures, a thick exoskeleton for protection against attack, and no worker caste. Members of this clade exploit other clades of the same general type of social insect. Species of the parasitic bee subgenus Psithyrus, which cladistically lies within the genus of their hosts, the bumblebees (Bombus), are good examples of this evolutionary model, as are members of the halictid bee subgenus Paralictus within Dialictus.

In this issue, Leppänen et al. (2016) present interesting data on mating isolation between macrogyne and microgyne populations of Myrmica rubra. The microgyne ants are workerless inquilines (social parasites) within the macrogyne colonies. Previous studies had suggested incomplete reproductive isolation between these sister populations of M. rubra.

However, it has been unclear how the mating system of Myrmica creates the opportunity for reproductive isolation between such sympatric populations of host and parasites. In a nicely designed set of genetic and mating compatibility tests, Leppänen and colleagues show that some ants prefer mate within their population, but that a small amount of cross-population gene flow likely occurs.

Leppänen et al. (2016) collected two kinds of data. First, they genotyped the gynes, worker, and males in colonies to determine the source of the males. In seven of the eleven nests studied, all males were produced by microgynes. In the remaining four colonies, males were produced either by macrogynes or by workers. Second, data on mating success of males were collected. Macrogyne (host) males mated more often with their own morphological type, whereas microgyne males seemed to succeed more evenly between the types/morphs.

The genetic differentiation between the two populations suggests speciation. Spatial separation of mating, with 
microgynes mating inside the nest and macrogynes mating in swarms, may explain the differentiation. The ability, however, of males to mate with either morphotype and the observation that microgyne males sometimes fly with swarms show that the evolutionary process that leads to mating isolation is incomplete in this system. To complete this story, a more thorough knowledge of the mating behavior of this species in the field will be required. Surprisingly little is known about the mating biology of many common species of ants, and gaining this knowledge will be difficult in examples like the microgynes of $M$. rubra, which mate within the nest.

Our understanding of the evolutionary processes that yield social parasites hinge on studies like this, which focus on species that are in an evolutionary dynamic state. Emery's rule acknowledges that sister species have "the keys to the kingdom" in terms of shared communicatory mechanisms but the rule has a major weakness in requiring genetic isolation of sympatric populations.

Generally, the relaxation of Emery's rule to incorporate species that have evolved in geographic isolation, and then come together, with one as host and the other as a parasite maintains the idea that commonality of social mechanism opens the door to parasitism, but that this can overlaid on a more plausible route to speciation. This study shows how genetic and behavioral data can be combined to help to shed light on these intriguing systems and that at least in some cases sympatric reproductive isolation should be considered as a mechanism.

Michael Breed,

Editor in Chief,

Insectes Sociaux

\section{Reference}

Leppänen J, Seppä P, Vepsäläinen K, Savolainen R (2016) Mating isolation between the ant Myrmica rubra and its microgynous social parasite. Insect Soc 63:79-86. doi:10.1007/s00040-0150438-y 